\title{
Audiology
}

\section{A mild phenotype of sensorineural hearing loss and palmoplantar keratoderma caused by a novel GJB2 dominant mutation}

\author{
Fenotipo lieve di sordità neurosensoriale e cheratoderma palmo-plantare causato \\ da una nuova mutazione dominante di GJB2

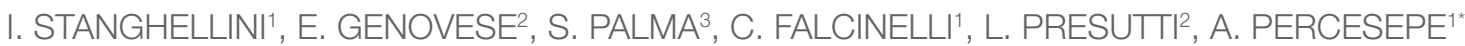 \\ ${ }^{1}$ Medical Genetics Unit, Department of Mother \& Child, University Hospital of Modena, Modena, Italy; ${ }^{2}$ Audiology \\ Service, Otolaryngology Department, University Hospital of Modena, Modena, Italy; ${ }^{3}$ Community Healthcare \\ Services, Otolaryngology Department, Modena, Italy \\ * present address: Medical Genetics, Department of Clinical and Experimental Medicine, University of Parma, Italy
}

\begin{abstract}
SUMMARY
Dominant GJB2 mutations are known to cause a syndromic form of sensorineural hearing loss associated with palmo-plantar skin manifestations. We present the genotype/phenotype correlations of a new GJB2 mutation identified in three generations of an Italian family (proband, mother and grandfather) whose members are affected by sensorineural hearing impairment associated with adult-onset palmoplantar keratoderma. In all affected members we identified a new heterozygous $G J B 2$ mutation (c.66G > T, p.Lys22Asn) whose segregation, population frequency and in silico prediction analysis have suggested a pathogenic role. The p.Lys22Asn GJB2 mutation causes a dominant form of hearing loss associated with variable expression of palmoplantar keratoderma, representing a model of full penetrance, with an age-dependent effect on the phenotype.
\end{abstract}

KEY WORDS: Hearing Loss $\bullet$ Sensorineural $\bullet$ Keratoderma $\bullet$ Palmoplantar $\bullet$ Gap junction beta-2 protein, human

\section{RIASSUNTO}

Le mutazioni dominanti del gene GJB2 sono causa di forme di sordità neurosensoriale sindromiche associate a manifestazioni cutanee palmo-plantari. In questo lavoro viene descritta la correlazione genotipo / fenotipo di una nuova mutazione nel gene GJB2 identificata in tre generazioni di una famiglia italiana (probando, madre e nonno) $i$ cui membri presentano ipoacusia neurosensoriale associata a cheratoderma palmo-plantare ad insorgenza nell'età adulta. Una nuova mutazione di GJB2 (c.66G > T, p.Lys22Asn) allo stato eterozigote è stata identificata in tutti membri affetti. La segregazione della mutazione, la sua frequenza nella popolazione generale e predizioni in silico ne attribuiscono un ruolo patogenetico. La mutazione p.Lys22Asn GJB2 determina una forma di sordità dominante associata ad un'espressione variabile di cheratoderma palmo-plantare, rappresentando un modello di penetranza completa con effetto età-dipendente sul fenotipo.

PAROLE CHIAVE: Sordità neurosensoriale • Cheratoderma palmo-plantare $\bullet$ GJB2

Acta Otorhinolaryngol Ital 2017;37:308-311

\section{Introduction}

Biallelic mutations in the GJB2 gene (MIM \#121011), encoding the gap junction protein Connexin 26, have been associated with non-syndromic hearing impairment (HI) of different degrees and audiometric patterns depending on the type (truncating vs non-truncating) and localization of the gene mutations ${ }^{12}$. Dominant mutations in the $G J B 2$ and in its contiguous homolog GJB6 have been also described in cases showing non-syndromic $\mathrm{HI}^{34}$ and in those with syndromic forms, characterised by an association between HI and skin manifestations, which in turn have been phenotyp- ically dissected into palmo-plantar keratoderma-deafness (PPKD, MIM \#148350), hystrixlike ichthyosis-deafness (HID, MIM \#602540), Bart-Pumphrey (MIM \#149200), keratitis-ichthyosis-deafness (KID, MIM \#148210) and Vohwinkel (MIM \#124500) syndromes ${ }^{56}$. The association between deafness and skin diseases has been proven as mutation specific, with about 20 causative GJB2 gene variants described to date, mainly affecting extracellular domain 1 of the connexin 26 protein ${ }^{7}$.

In the present report we describe a new GJB2 mutation, c.66G > T (p.Lys22Asn), identified in an Italian pedigree with carriers showing moderate, progressive sensorineu- 
ral HI and age-dependent palmoplantar keratoderma suggesting full penetrance and variable expression.

\section{Materials and methods}

Patients were recruited at Modena University Hospital and evaluated by otolaryngologists and medical geneticists. Clinical, auditory and genetic data, including family medical histories with special care towards deafness and age of HI onset were collected. Hearing thresholds were measured by pure tone audiometry at the frequencies of $0.25,0.5,1$, 2, 3, 4 and $6.8 \mathrm{kHz}$; auditory brainstem response (ABR) was performed in case of asymmetry. Analysis of the GJB2 gene was performed on DNA extracted from blood after informed consent, as previously described ${ }^{8}$.

The study was approved by the local Ethics Committee (Protocol No. 108/14).

\section{Results}

The proband (III-2, Fig. 1) is a 7-year-old child presenting asymmetric bilateral high-frequency sensorineural HI, with a threshold around $15 \mathrm{~dB}$ at $250-4000 \mathrm{~Hz}$, sloping down to $60 \mathrm{~dB}$ at the $8000 \mathrm{~Hz}$ frequencies (Fig. 1) in the right ear, while the left ear had a slope to $40 \mathrm{db}$ at 2000$4000 \mathrm{hz}$, reaching $60 \mathrm{db}$ at $8000 \mathrm{~Hz}$. Among the relatives, his half-sister (same mother, different father) had a unilateral sensorineural HI, which was limited to $8000 \mathrm{~Hz}$ with a threshold around $70 \mathrm{~dB}$, presently involving only the right ear. The mother (clinical diagnosis of $\mathrm{HI}$ around 9 years of age) and maternal grandfather both had similar, but more severe audiometric patterns, which were referred to as progressive through the years (Fig. 1 reports their audiograms performed at 46 and 78 years of age, respectively).

Dermatological examination of the adult affected members of the family (patient II-2, and patient I-1 of Fig. 1) showed a variable expression of adult-onset palmoplantar keratoderma, which was diffuse on the palms and soles without any involvement of the dorsal side of the hands, feet or of the nails and a friction-associated denuded area of the fingertips (Fig. 2, panel B). Neither children had the palmo-plantar phenotype.

Sequencing analysis of the GJB2 gene revealed a novel heterozygous variant, c.66G $>\mathrm{T}$, p.Lys22Asn (Fig. 3A) (ClinVar ID 242831, http://www.ncbi.nlm.nih.gov/clinvar/), which was present in patients III-2, III-1, II-2, I-1, all showing some degree of HI, thus suggesting an autosomal dominant pattern of inheritance. The mutation, falling in the transmembrane domain of the connexin 26 protein (Fig. $3 \mathrm{~B}$ ), has not been previously reported in the medical literature, is not present in the public disease databases (Leiden Open variant Database ${ }^{9}$, Deafness Variation Database, The Molecular Otolaryngology and Renal Research Laboratories, The University of Iowa), or as a variant in the general population (Ensembl ${ }^{10} ; 1000 \mathrm{Ge}$ nomes Project Consortium ${ }^{11}$, Exome Variant Server). The Polymorphism Phenotyping v2 ${ }^{12}$, Provean ${ }^{13}$, Mutation Tester ${ }^{14}$ tools, which were used to predict the possible impact of the amino acid substitution on the structure and function of the protein, classified the variant as pathogenic (Polyphen-2 prediction: probably damaging with a score of 1.000, sensitivity: 0.00; specificity: 1.00 ; Provean prediction deleterious with a score of -2.716 ; Mutation tester prediction: disease causing prob $>0.99$ ).

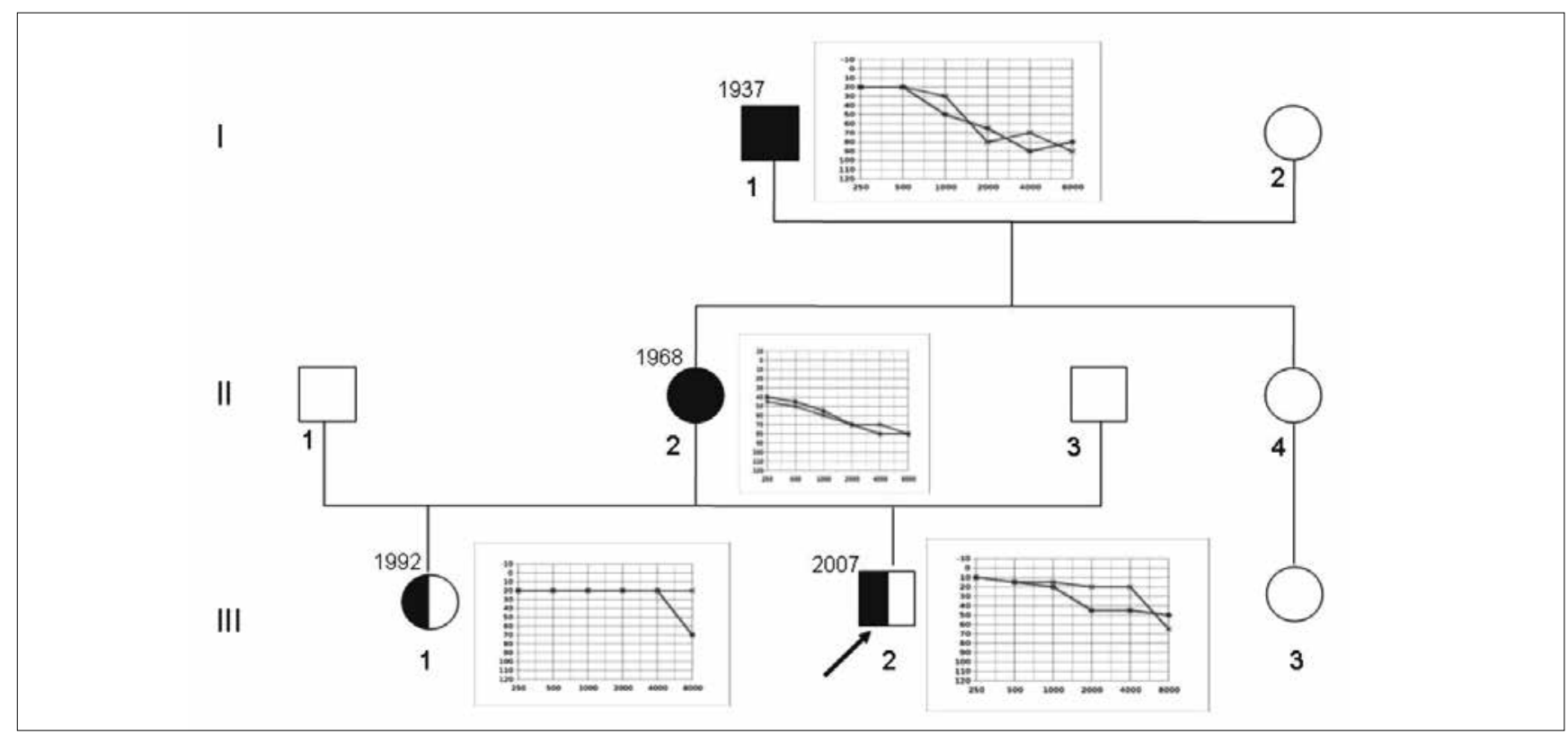

Fig. 1. Genealogical tree of the family under study. Hearing impairment and PKK is indicated by solid-filled shapes. Half-shaded symbols denote non-syndromic HI. The audiograms were obtained at age 78, 46, 23, 7 for patients I-1 , II-2, III-1, III-2, respectively. The arrow indicates the proband. 

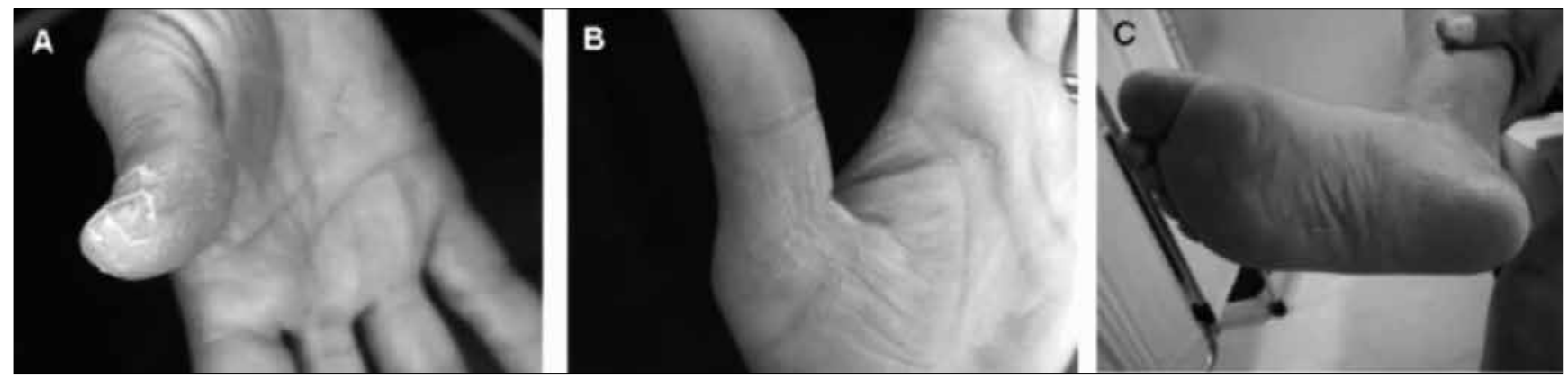

Fig. 2. Skin changes of the hands (A and B) and feet (C) of patient II-2 in Figure 1, demonstrating a palmoplantar keratoderma with a friction-associated denuded area of the thumb fingertip.

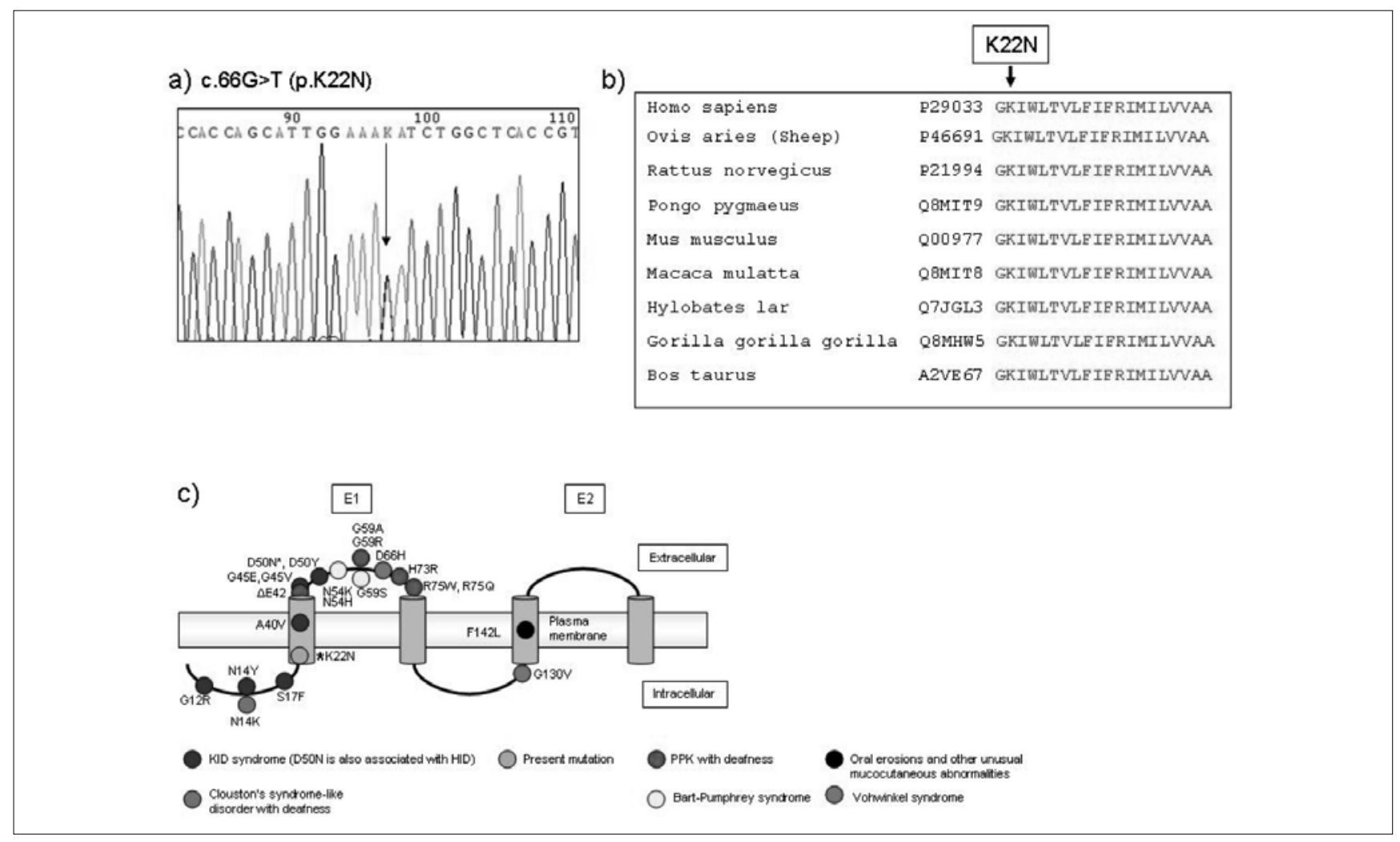

Fig. 3. a) Proband's chromatograms of GJB2. The arrow indicates the position of the c.66G>T, p.Lys22Asn mutation. b) Comparison of amino acid sequences of GJB2 among diverse species, showing that the first transmembrane domain (from aa 21 to aa 40) is highly conserved. c) GJB2-associated syndromes and reported causative mutations. E1 and E2, extracellular domains 1 and 2, respectively; PPK, palmoplantarkeratoderma; KID, keratitis-ichthyosis-deafness.

\section{Discussion}

We report a novel GJB2 dominant mutation identified in an Italian pedigree, associated with childhood-onset, progressive neurosensorial HI and palmoplantar keratoderma, which was observed only in the adult affected members of the family. Different from the other keratoderma/deafness causing mutations, the p.Lys22Asn GJB2 variant resides in the transmembrane domain (TM) of the Cx26 protein, which contributes to cell-to-cell interaction at the level of the connexin hemichannels ${ }^{(15)}$. In one of the TM domains, only one other mutation has been described so far, namely p.Phe142Leu in which the affected child presented an unusual dermatologic phenotype characterised by vast erythematous patches on the trunk and mu- cosae without keratoderma ${ }^{16}$. The reported phenotype of the family falls into the spectrum of the dominant $G J B 2$ mutations described so far, since it progressively affects the auditory function starting from the highest frequencies in a mild and non-symmetrical fashion (Fig. 1, patients III-1 and III-2) and finally arrives to a moderate to severe degree of $\mathrm{HI}$ in the adult affected members of the family (patient I-1, Fig. 1). The dermatological features also appear mild, adult-onset and progressive, in keeping with the hypothesis of the p.Lys22Asn variant as a mild modifier of skin homeostasis with a gene dosage effect becoming apparent only with ageing.

Although a functional confirmation of the weak pathogenic potential of the variant is needed for definitive 
evidence, the presented genotype/phenotype correlations show that the p.Lys22Asn can be considered as a variant with full but age-dependent penetrance, which initially causes an auditory and dermatological phenotype just above the threshold for clinical detection and becomes more evident with ageing, simulating the paradigm of other multifactorial disorders, like age-related hearing loss itself, which has been associated with the susceptibility effect produced by low-penetrance genes ${ }^{17}$.

\section{Conclusions}

In conclusion, based on patients' phenotype, mutation segregation, population frequency and in silico prediction analysis, we suggest that the p.Lys22Asn variant is the cause of the dominant form of hearing loss associated with a variable expression of palmoplantar keratoderma in the family under study and represents a model of full penetrance, with an age-dependent effect on the phenotype.

\section{Acknowledgements}

I.S. was granted by Programma di ricerca Regione-Università 2010-2012, Strategic Programme "Next-generation sequencing and gene therapy to diagnose and cure rare diseases in Regione Emilia Romagna (RER)".

\section{Web resources}

Online Mendelian Inheritance in Man (OMIM), http:// www.omim.org/

Deafness Variation Database, http://deafnessvariationdatabase.org/, accessed April 52016

Molecular Otolaryngology and Renal Research Laboratories, http://www.medicine.uiowa.edu/morl/

Exome Sequencing Project http://evs.gs.washington.edu/ EVS/, accessed April 52016

\section{References}

1 Snoeckx RL, Huygen PL, Feldmann D, et al. GJB2 mutations and degree of hearing loss: a multicenter study. Am J Hum Genet 2005;77:945-57.

2 Putcha GV, Bejjani BA, Bleoo S, et al. A multicenter study of the frequency and distribution of GJB2 and GJB6 mutations in a large North American cohort. Genet Med 2007;9:413-26.
3 Feldmann D, Denoyelle F, Blons H, et al. The GJB2 mutation $R 75 Q$ can cause nonsyndromic hearing loss DFNA3 or hereditary palmoplantar keratoderma with deafness. Am J Med Genet A 2005;137:225-7.

4 Berger AC1, Kelly JJ, Lajoie P, et al. Mutations in Cx30 that are linked to skin disease and non-syndromic hearing loss exhibit several distinct cellular pathologies. J Cell Sci 2014;127:1751-64.

5 Heathcote K, Syrris P, Carter ND, et al. A connexin 26 mutation causes a syndrome of sensorineural hearing loss and palmoplantar hyperkeratosis (MIM 148350). J Med Genet 2000;37:50-1.

6 Nemoto-Hasebe I, Akiyama M, Kudo S, et al. Novel mutation p.Gly59Arg in GJB6 encoding connexin 30 underlies palmoplantar keratoderma with pseudoainhum, knuckle pads and hearing loss. Br J Dermatol 2009;161:452-5.

7 de Zwart-Storm EA, Hamm H, Stoevesandt J, et al. A novel missense mutation in GJB2 disturbs gap junction protein transport and causes focal palmoplantar keratoderma with deafness. J Med Genet 2008 Mar;45:161-6.

8 Stanghellini I, Genovese E, Palma S, et al. New and rare GJB2 alleles in patients with nonsyndromic sensorineural hearing impairment: a genotype/auditory phenotype correlation. Genet Test Mol Biomarkers 2014;18:839-44.

9 Fokkema IF, Taschner PE, Schaafsma GC, et al. LOVD v.2.0: the next generation in gene variant databases. Hum Mutat 2011;32:557-63.

10 Herrero J, Muffato M, Beal K, et al. Ensembl comparative genomics resources. Database (Oxford) 2016 pii:bav096.

111000 Genomes Project Consortium, Abecasis GR, Auton A, et al. An integrated map of genetic variation from 1,092 $\mathrm{hu}$ man genomes. Nature 2012;491:56-65.

12 Adzhubei IA, Schmidt S, Peshkin L, et al. A method and server for predicting damaging missense mutations. Nat Methods 2010;7:248-9.

13 Choi Y, Sims GE, Murphy S, et al. Predicting the functional effect of amino acid substitutions and indels. PLoS One 2012;7:e46688.

14 Schwarz JM, Cooper DN, Schuelke M, et al. MutationTaster2: mutation prediction for the deep-sequencing age. Nat Methods 2014;11:361-2.

15 Zhou JZ, Jiang JX. Gap junction and hemichannel-independent actions of connexins on cell and tissue functions - an update. FEBS Lett 2014;588:1186-92.

16 Brown CW, Levy ML, Flaitz CM, et al. A novel GJB2 (connexin 26) mutation, F142L, in a patient with unusual mucocutaneous findings and deafness. J Invest Dermatol 2003;121:1221-3

17 Kochhar A, Hildebrand MS, Smith RJ. Clinical aspects of hereditary hearing loss. Genet Med 2007;9:393-408. 